УДК 009+339.543

\title{
ОТЕЧЕСТВЕННЫЙ И ЗАРУБЕЖНЫЙ ОПЫТ ЛОГИСТИЗАЦИИ ПЕРЕМЕЩЕНИЯ ТОВАРОВ АВТОМОБИЛЬНЫМ ТРАНСПОРТОМ ЧЕРЕЗ ТАМОЖЕННУЮ ГРАНИЦУ
}

\author{
С.В. БОРИСЮК, \\ заместитель председателя Государственного таможенного комитета \\ Республики Беларусь, г. Минск
}

\begin{abstract}
Аннотация
В настоящей статье проанализирован зарубежный опыт логистизации перемещения товаров через таможенную гранииу. Автор статьи положси в основу своих рассуждений зарубежный опыт с иелью выработки оптимальной отечественной модели логистизащии перемещения товаров автомобильным транспортом.

Ключевые слова: логистизация, перемещение товаров, грузотранспортировка, логистика.
\end{abstract}

\section{Abstract}

This article analyzes the international experience of «logistization» of movement of goods across the customs border. The author has based his reasoning foreign experience to develop optimal domestic model «logistization» of movement of goods by road.

Key words: «logistization», movement of goods, cargo transport, logistics.

\section{ВВЕДЕНИЕ}

Научный интерес к таможенной логистике в настоящее время проявляют ученые всего мира. Подобное научное познание, по всей видимости, обусловлено тем, что к отмеченной теме привлечено пристальное внимание влиятельных международных организаций, в числе которых, прежде всего Организация Объединенных наций (далее $\mathrm{OOH})$, Всемирная торговая организация (далее - ГАТТ/ВТО), Всемирная таможенная организация (далее - СТС/ВТО). Упрощение процедур торговли и транспортного обслуживания обретает все большее значение для конкурентоспособности стран и их потенциала в области экономического развития. Развивающимся странам оказывается всестороннее содействие в проведении исследовательской, аналитической, консультационной работы, а также технической помощи по упрощению торговых процедур («to facilitate trade»). В большей степени эта работа проводится Европейской Экономической Комиссией ООН (далее - ЕЭК ООН) и Конференцией ООН по торговле и развитию (далее - ЮНКТАД).

Региональные организации также заинтересованы к участию в подобных форумах, программах, обсуждениях. Они в свою очередь, привлекают ученых и различных экспертов к актуальной в настоящее время проблеме. Интерес региональных блоков еще более прагматичный, так как его конечная цель привлечение новых партнеров, способных участвовать в логистической цепи поставок, т.е. быть полноправным членом интеграционного блока, что мы наблюдаем в нашем регионе. Индия, Китай и иные государства готовы к партнерству с ЕАЭС, что обусловлено их геополитическим положением и развитой логистической инфраструктурой. 


\section{РЕЗУЛЬТАТЫ И ИХ ОБСУЖДЕНИЕ}

Стоит отметить, что упрощение процедур торговли и транспортного обслуживания находится в неразрывной взаимосвязи и взаимозависимости с общим экономическим уровнем страны. Велика роль упрощения процедур торговли и транспортного обслуживания в развитии транзитных перевозок и реализации транзитного потенциала, что чрезвычайно актуально для Республики Беларусь.

В действительности в статье мы попытаемся учесть опыт различных регионов, а вместе с тем позицию международных организаций по данному вопросу.

С этой целью для оценки развития логистических систем различных стран специалистами Всемирного банка с целью их сравнения был разработан Индекс эффективности логистической системы (Logistics Performance Index-LPI).

Европейские и американские ученые рассчитывают по шкале до 7-и баллов. Например, Jaime Mejia [1, с. 68], утверждает, что эффективная деятельность таможни играет решающее значение для торговли и организации логистического процесса, так как в большей степени формирует конечную стоимость продукции. Она приводит в своей статье данные Межамериканского банка развития, которые говорят о том, что каждый день ожидания груза на таможне способен сократить торговлю на 1 \%. Данное влияние еще более фатально для скоропортящихся товаров - 7\%. Известный эксперт Межамериканского банка развития Manuel Marquez Farina полагает, что государства Латинской Америки способны получать от 30 до 50 \% налоговых поступлений страны, если перестанут быть отстающими государствами. Рейтинг логистики государств Латинской Америки составляет 1 балл, по сравнению с максимальным рейтингом ЕС 7 баллов и США - примерно 5 баллов [2, с. 78; 3, с. 134; 4, с. 16-18].

Раз в два года Всемирный банк публикует рейтинг стран, составленный на основе этого индекса. Впервые в 2007 г. Всемирным Банком были проведены исследования индекса развития логистик и 150 стран мир а, а в 2010 г. - 155.

Как отмечают исследователи нашего региона, вопрос оценки и сравнения логистической среды различных стран является достаточно сложным. Расчет итогового индекса сделан по 5-ти балльной шкале (где 5 - наивысший балл) на основе средневзвешенной оценки 6 базовых индикаторов: 1) таможня (эффективность и прозрачность таможенных процедур); 2) инфраструктура (качество транспортной инфраструктуры и информационных технологий для логистики); 3) международные поставки (простота и доступность при организации международных перевозок); 4) качество и компетенция в сфере логистики (качество и компетенция региональной логистической среды, компетентность сотрудников логистической инфраструктуры); 5) отслеживание грузов (возможность отслеживания международных грузов); 6) своевременность (своевременность доставки груза к пункту назначения) [5, с. 175].

При расчете индекса логистики Всемирный банк наибольшее внимание уделяет на условия создания в стране сквозного управления материальными потоками, а также на простоту и эффективность проведения таможенных процедур. Так из 55 вопросов, позволяющих оценить состояние логистической системы, 20 относятся к эффективности работы таможенных органов, 10 - к уровню развития логистики, 8 - к общим условиям осуществления торговли, 5 - к эффективности работы контрольных органов и только 4 вопроса - непосредственно к работе транспорта [6].

Как видно из предыдущего тезиса, вопрос эффективности таможенной логистики является наиболее приоритетным, нежели транспортной логистики, что еще раз подтверждает актуальность темы исследования.

Ориентируясь на логистику перемещения товаров автомобильным транспортом стоит, прежде всего, отметить, что текущее состояние международных грузовых автомобильных перевозчиков Беларуси показало, что на начало 2013 года парк автомобильных транспортных средств, зарегистрированных для осуществления международных перевозок по процедуре МДП, составил 11700 единиц, при этом фактически использовалось 
немногим более 9 тыс. единиц. В последние годы наблюдается высокий темп роста числа международных перевозчиков. Стоит учесть, что парк их транспортных средств достаточно новый. Так, доля автомобильных транспортных средств со сроком эксплуатации «до 3-х лет» составила более $37 \%$, «от 3 до 7 лет» - более $35 \%$. При этом более 50 \% автомобилей отвечают экологическим требованиям ЕВРО-4 и ЕВРО-5.

Объем международных перевозок грузов автомобильным транспортом Республики Беларусь растет на протяжении последних лет и в 2012 г. по сравнению с 2010 г. он увеличился более чем на 35 \% [7; 8, с. 5-6].

По белорусским автодорогам через пункты пропуска на белорусско-литовском и белорусско-польском участках Государственной границы в 2012 г. проследовало транзитом 1380 тыс. грузовых автомобилей (в обоих направлениях), что составило 82 \% транзитных поездок через Республику Беларусь. Объем перевозок составил более 12 млн. тонн, или 82 \% транзита грузов автотранспортом через Республику Беларусь. Средний темп роста транзита грузов автотранспортом через Беларусь за 2008-2012 гг. составил $111 \%$ в год.

Учитывая качественное состояние дорожной инфраструктуры, которая с каждым годом улучшается во исполнение требования Президента Республики Беларусь, а также заинтересованность самих таможенных перевозчиков конкурировать с иностранными перевозчиками, можно уверенно сказать, что логистическая инфраструктура совершенствуется. Сушественным аргументом улучшения качества логистического сектора является предоставление дополнительных преференций и привилегий субъектам отмеченной сферы.

В настоящее время в Республике Беларусь функционируют 50 логистических центров: «Брест-Белтаможсервис», «Минск-Белтаможсервис», «Минск-Белтаможсервис-2», «Гомель-Белтаможсервис», СООО «Брествнештранс», ИП «БЛТ-Логистик», ООО «Двадцать четыре», ОАО «Белмагистральавтотранс», ОАО «Озерцо-Логистик», СООО «БелВингесЛогистик», ТЧУП «ШАТЕ-М Плюс», ООО «ИнтерСтройПорталПлюс», ИООО «Логистический центр «Прилесье» и проч.

Услуги логистических центров Республики Беларусь, предоставляемые таможенным перевозчикам, практически одинаковые: транспортировка, таможенные формальности, временное размещение и хранение материальных запасов; преобразования материальных потоков, обеспечение логистического сервиса в системе обслуживания.

Следует признать, что на 23,5 \% увеличилось и количество перевозок грузов, выполненных иностранными перевозчиками. Объем перевезенных грузов в / из Республики Беларусь белорусскими и иностранными перевозчиками (включая перевозки в / из «третьих стран») за 2010 г. в целом составил 4,54 млн. т. (на 13 \% выше уровня 2009 г.), в том числе 1,86 млн. т. перевезено иностранными перевозчиками и 2,68 млн. т. - белорусскими.

При этом стоит заметить, что удельный вес данных перевозок мог быть существенно выше. Причина в несовершенной таможенной логистике, ошибки которой необходимо в ближайшее время устранить.

Как известно, таможенные органы Республики Беларусь осуществляют различные виды государственного контроля, одним из которых является автомобильный контроль. Задачей инспектора таможни в рамках осуществляемого автомобильного контроля является проверка разрешительных документов на въезд на территорию Республики Беларусь, либо, если товары следуют транзитом, проверяются аналогичные разрешительные документы страны назначения товара при въезде. Таким образом, Республика Беларусь не имеет двусторонних соглашений о международном автомобильном сообщении со всеми государствами, заключенными между государствами на уровне правительств. Для сравнения, Российская Федерация имеет подобные соглашения практически со всеми государствами ЕС, кроме Португалии, а также с государствами, с которыми есть общая таможенная граница. 
В ином случае, если перемещение автотранспортных средств осуществляются между странами, не заключившими между собой двусторонних соглашений, разрешения могут выдаваться в разовом порядке при обращении к компетентным органам или эти органы могут в одностороннем порядке устанавливать контингент разрешений для перевозчиков другой страны.

Стоит заметить, что в самом начале широкого развития международных автомобильных перевозок в 1958 в Женеве было принято Соглашение о принятии единообразных условий утверждения и признания предметов оборудования и частей механических транспортных средств. Россия присоединилась к этому Соглашению в 1987 г., что обусловило введение в этом государстве сертификации автотранспорта. В связи с этим требуется приведение законодательства ЕАЭС в соответствие с Женевским соглашением, а именно введение автотранспортной сертификации в государствах-участниках ЕАЭС.

С учетом международного опыта, любая экономическая интеграция сопровождается различного рода проблемами и трудностями. Часть из них связана с отработкой норм унифицированного таможенного законодательства на практике.

Действующий ТК ТС содержит много отсылочных норм к законодательству государства - члена таможенного союза. Считалось, что все проблемы подобного рода будут разрешены после унификации национального законодательства. Однако членство России в ГАТТ/ВТО и расширение границ провоцируют новые трудности. Тем самым, приведение законодательства теперь становится как ни когда актуальным и более острым. Также на повестке дня вопросы присоединения к европейским конвенциям для обеспечения единых правил и таможенных процедур.

Между тем, в Республике Беларусь транспортное законодательство признано как наиболее прогрессивное, по сравнению с государствами-членами ЕАЭС и СНГ.

В настоящее время все действующие документы можно свести к следующим основным группам:

- требования к транспортным средствам;

- правила, организация и безопасность движения транспортных средств по автомобильным дорогам;

- требования к водителям транспортных средств и организации их труда;

- условия выполнения международных автомобильных перевозок;

- права, обязанности, ответственность сторон, участвующих в перевозочном процессе;

- правила пограничного и таможенного контроля;

- налогообложение перевозок и транспортных средств.

К основным международным документам, регламентирующим транснациональные грузоперевозки относятся:

- Конвенция о договоре международной перевозки грузов (КДПГ, 1956);

-Протокол ООН 5 июля 1978 г. к Конвенции о договоре международной дорожной перевозки грузов (КДПГ, 1956);

- Таможенная Конвенция о международной перевозке грузов с применением книжки МДП (1959, в ред. 1975);

- Европейское соглашение, касающееся работы экипажей транспортных средств, производящих международные автомобильные перевозки (ECTD, 1970);

- Соглашение о международных перевозках скоропортящихся пищевых продуктов и о специальных транспортных средствах, предназначенных для этих перевозок (СПС, 1970);

-Европейское соглашение о международной дорожной перевозке опасных грузов (1957).

Подводя промежуточный итог, можно сказать, что в Республике Беларусь законодательные акты довольно широко охватывают сферу международных грузоперевозок, если сравнивать с государствами-партнерами по ЕАЭС. Имеются практически все ключевые законодательные акты по основным направлениям. Вместе с тем, существует ряд 
существенных проблем, которые требуют гармонизации белорусского и европейского законодательства в области международных грузоперевозок, а именно:

1. Не гармонизировано базовое законодательство в сфере автотранспортной деятельности. Полагаем необходимо предусмотреть возможность унификации целого ряда положений уставов, кодексов и законов в области автотранспорта государств-членов ЕАЭС и СНГ. Существуют такие прецеденты, когда в отдельных государствах законодательные акты отсутствуют либо регулирование данных правоотношений осуществляется на основе устаревших законов, что неприемлемо. Зачастую подобная прореха в законодательстве сказывается на непоступлении таможенных сборов в бюджет государства либо на безопасности перевозок опасных грузов. Все это накладывает дополнительные сложности во взаимодействии международных перевозчиков с органами государственного управления, а также их контагентами по сделкам.

2. Остаются не унифицированными технические стандарты и технологические нормы в сфере автомобильных перевозок. Так, из всего числа международных договоров ЕЭК ООН - 40 договоров, прямо либо косвенно затрагивающих сфере автомобильных перевозок, 11 не подписало ни одно государство-участник ЕврАзЭС. Исключение составляет Таможенная конвенция о международной перевозке грузов с применением книжки МДП (1975 г.), к которой присоединились все государства-члены ЕврАзЭС.

3. Отсутствие эффективной разрешительной системы на территории ЕврАзЭС. Двусторонние соглашения, заключенные между отдельными странами, предполагают различный уровень преференций в отношении налогов, дорожных сборов, транзита, предусматривают в ряде случаев разрешительную систему осуществления перевозок, в том числе и на основе согласования контингента выдаваемых разрешений.

4. Сохраняются различные барьеры технического, административного, фискального и трансграничного характера, что противоречит требованиям ГАТТ/ВТО, а также Рамочным стандартам безопасности и облегчения мировой торговли [9].

Учитывая все перечисленные упущения, связанные с несовершенством законодательства в данной области, необходимо разработать план мероприятий по оптимизации таможенной и транспортной логистики в Республике Беларусь.

1. Осуществить инвентаризацию всех правовых актов Республики Беларусь, регулирующих данные правоотношения, на предмет соответствия современным требованиям, продиктованным ЕЭК ООН, СТС/ВТО, ГАТТ/ВТО и иными международными организациями и союзами.

2. Согласовать межгосударственную позицию стран-членов ЕАЭС и, возможно, СНГ на предмет несоответствия национального законодательства международным договорам и разработать предложения по их устранению.

3. Продолжить работу по присоединению к международным договорам ЕЭК $\mathrm{OOH}$, а также ратифицировать подписанные договоры.

4. Унифицировать транспортные технические нормы и стандарты, поскольку это важнейший элемент согласованной интеграции ЕврАзЭС в европейскую и мировую транспортные системы.

5. Создать эффективную систему осуществления международных автомобильных сообщений между государствами-членами ЕврАзЭС через ликвидацию административных барьеров. Для этого необходимо устранить барьеры в области платы за транзит, дорожных и иных сборов за проезд по бесплатным дорогам, разрешительной системы при осуществлении двусторонних перевозок в рамках СНГ, доставки тяжеловесных, негабаритных и опасных грузов.

Подводя черту высказанным предложениям, следует отметить, что их реализация в ближайшее время позволит оценить существенный рост в объеме автомобильных перевозок по таможенной территории ЕАЭС и государств-членов СНГ.

Помимо совершенствования законодательства в сфере автомобильных перевозок существует ряд системных практических вопросов, требующих дополнительного вни- 
мания таможенных органов и иных уполномоченных органов, являющихся субъектами таможенной логистики.

С целью сокращения времени пребывания автомобильного транспортного средства в зоне таможенного контроля на момент проведения таможенных операций и таможенного контроля необходимо:

1. Внедрять по периметру всей таможенной границы в автомобильных пунктах пропуска современные информационные технологии таможенного контроля (мобильные инспекционно-досмотровые комплексы (далее - МИДК)). Полагаем, применение МИДК позволит проводить таможенный досмотр автомобильных транспортных средств не более, чем 0,5 \% транспортных средств, перемещающихся транзитом.

2. Совершенствовать реализацию принципов «две службы на границе» и «одна остановка». Внедрение данной технологии показало, что время простоя транспортных средств в пограничных пунктах пропуска сократилось примерно в 2 раза. Подробнее об этом будет сказано позже.

3. Обеспечить полный охват автоматизированной системой электронного предварительного информирования товаров, перевозимых автотранспортом через Государственную границу Республики Беларусь. Это позволит примерно в 1,5 раза сократить время, затрачиваемое на пропуск товаров в пограничных пунктах пропуска.

Так, с 1 марта 2011 года введено обязательное предварительное информирование таможенных органов ЕС обо всех грузах, которые ввозятся на территорию ЕС в целях обработки в системе анализа рисков до прибытия груза на территорию ЕС. Для этого в таможенные органы страны ввоза необходимо подать определенные данные - так называемую декларацию о ввозимом грузе (entry summary declaration). Объем необходимых для обработки данных, а также время подачи декларации зависит от вида транспорта, в котором перемещаются товары.

При перевозке груза автомобильным транспортом, такая декларация должна быть подана не менее чем за 1 час до его фактического прибытия на территорию ЕС. Для сравнения: при железнодорожных перевозках - за 2 часа, при авиаперевозках - до фактического отправления воздушного судна (при длительных рейсах - как минимум за 4 часа до прибытия воздушного судна в ЕС). Подать эти данные можно только в электронном виде, используя Систему контроля импорта или Систему контроля транзита.

4. Достичь договоренности по использованию положения ст. 79 ТК ТС [10] в части предоставления права резидентам Республики Беларусь производить таможенное декларирование в отношении груза, следующего в адрес субъектов России и Казахстана. Для этого продолжить переговоры по отмене требований российской стороны к белорусским перевозчикам по наличию разрешений третьих стран при перевозке транзитных грузов, обработанных на логистических центрах Республики Беларусь.

5. Внести поправки в Соглашение между Правительством Республики Беларусь и Правительством Российской Федерации «О принципах взимания косвенных налогов при экспорте и импорте товаров, выполнении работ, оказании услуг» от 1 января 2005 г. [11] и в Соглашение между Правительством Республики Беларусь и Правительством Республики Казахстан «О принципах взимания косвенных налогов при экспорте и импорте товаров (работ)» от 1 сентября 1999 г. [12] в части, касающейся предоставления отсрочки по уплате НДС до 180 календарных дней, для резидентов Республики Беларусь, осуществивших таможенное декларирование груза, следующего в адрес субъектов хозяйствования России и Казахстана.

6. Разработать механизм взимания косвенных налогов при отмене принципа «резидентства» при осуществлении таможенных операций.

7. Упростить процедуру таможенного декларирования товаров, находящихся под таможенным контролем в ТЛЦ.

8. Для сокращения времени и упрощения документооборота при оказании логистических услуг использовать средства автоматизации и унификации транспортных и товарно-транспортных документов, поэтапно внедрять автоматизированные системы 
управления транспортно-логистическими центрами, в соответствии с государственными программами информатизации, автоматизации и развития транзитного потенциала Республики Беларусь.

9. Инициировать переговорный процесс на уровне ЕЭК с транспортными ведомствами государств-членов ЕАЭС и ЕС. После чего присоединиться к европейским конвенциям по транзиту, что даст возможность стать частью транспортного коридора «Западная Европа - Западный Китай» Республике Беларусь. Присоединение Республики Беларусь к транспортному коридору «Западная Европа - Западный Китай» возможно за счет включения в него ответвления через республику по II и IX международным транспортным коридорам в направлении к западной границе ЕАЭС и портам Балтийского моря через автодорожные пункты пропуска «Козловичи» и «Каменный Лог».

Европейская Конвенция об общей транзитной процедуре [13] позволит перевозить грузы автомобильным транспортом, равно как и иными видами транспорта с минимальными таможенными формальностями:

Общий метод транзита включает три ключевых элемента:

1) единый административный документ (Single Administrative Document - SAD) [14];

2) систему поручительства, обеспечивающую гарантию доставки груза в место назначения;

3) электронную систему обработки данных (New Computerised Transit System NCTS) [15].

Электронная система обработки данных - общеевропейская компьютеризированная система позволит упразднить бумажный документооборот при транзитных перевозках между странами.

\section{ВЫВОДЫ}

Подводя итог настоящей статье, сформулируем следующие выводы.

В основе роста показателей автомобильных перевозок товаров через таможенную границу заложена эффективная таможенная и транспортная логистика как неразрывные части процесса.

1. Предложено гармонизировать и унифицировать транспортное и таможенное законодательство со всеми государствами-членами ЕАЭС, что позволит создать безбарьерную среду для перемещения товаров по процедуре таможенного транзита. Инициировать переговорный процесс на уровне ЕЭК с транспортными ведомствами государств-членов ЕАЭС и ЕС для последующего присоединения к европейским конвенциям по транзиту и иным международным договорам ЕЭК ООН по вопросам перевозок.

2. Предложены практические шаги по совершенствованию таможенной логистики в отношении автомобильных перевозок товаров через таможенную границу:

1) внедрить по периметру всей таможенной границы в автомобильных пунктах пропуска современные информационные технологии таможенного контроля;

2) совершенствовать реализацию принципов «две службы на границе» и «одна остановка»;

3) обеспечить полный охват автоматизированной системой электронного предварительного информирования товаров, перевозимых автотранспортом через Государственную границу Республики Беларусь;

4) достичь договоренности по использованию положения ст. 79 ТК ТС [10] в части предоставления права резидентам Республики Беларусь производить таможенное декларирование в отношении груза, следующего в адрес субъектов России и Казахстана;

5) разработать механизм взимания косвенных налогов при отмене принципа «резидентства» при осуществлении таможенных операций;

6) упростить процедуру таможенного декларирования товаров, находящихся под таможенным контролем в ТЛЦ; 
7) внедрять автоматизированные системы управления транспортнологистическими центрами, в соответствии с государственными программами информатизации, автоматизации и развития транзитного потенциала Республики Беларусь;

8) продолжать минимизировать таможенные формальности в контексте присоединения к Европейской Конвенции об общей транзитной процедуре.

\section{ЛИТЕРАТУРА}

1. Jaime Mejia Customs, a serious obstacle / Jaime Mejia // Latin Trade. - SeptemberOctober - 2014. - P. 68.

2. The handbook of logistics $\&$ distribution management $4^{\text {th }}$ edition, edited by Alan Rushton, Phil Croucher, Peter Baker 2010.

3. Джонсонс Дж., Вуд Д., Вордлоу Ф. и др. Современная логистика М:, Издательский Дом «Вильямс», 2002, - 624 с.

4. Ritu Rooney The Labyrinth of Global Customs / Ritu Rooney // Global Trade. September-October-2011. - P. 16-18.

5. Ивуть, Р.Б. теоретические и практические аспекты развития логистической системы Республики Беларусь Р.Б. Ивуть, В.В. Равино, Н.В. Стефанович Каспийский регион: политика, экономика, культура научный журнал 2011, № 4 (29). - с. 170-177.

6. Сайт Всемирного банка. - Режим доступа: http://data.worldbank.org, свободный

7. Апанасович, В.В. Молокович, А.Д. Исследование транспортно-логистической системы Республики Беларусь. - с. 5-16.

8. Современные концепции развития транспорта и логистики в Республике Беларусь : сборник статей / сост. : В.В. Апанасович, А.Д. Молокович. - Минск : Центр «БАМЭ- Экспедитор», 2014. - 320 с.

9. Рамочные стандарты безопасности и облегчения мировой торговли [Электронный ресурс] : 23 июня 2005 г. // Всемирная таможенная организация. - Режим доступа: http://www.wcoomd.org/en/about-us/what-is-the-wco/ / /media/106B5B41F4C34C9F87EB B5DBC0887651.ashx. - Дата доступа: 01.04.2015.

10. Таможенный кодекс таможенного союза : Закон Респ. Беларусь от 2 июля 2010 г. № 158-3 : принят Межгос. Советом Евраз. экон. сообщества 27 нояб. 2009 г. 3-е изд. - Минск : Белтаможсервис, 2014. - 303 с.

11. О принципах взимания косвенных налогов при экспорте и импорте товаров, выполнении работ, оказании услуг : Соглашение между Правительством Республики Беларусь и Правительством Российской Федерации от 1 января 2005 г.

12. О принципах взимания косвенных налогов при экспорте и импорте товаров (работ) : Соглашение между Правительством Республики Беларусь и Правительством Республики Казахстан от 1 сентября 1999 г.

13. Европейская Конвенция об общей транзитной процедуре Convention between the European Economic Community, the Republic of Austria, the Republic of Finland, the Republic of Iceland, the Kingdom of Norway, the Kingdom of Sweden and the Swiss Confederation, on a common transit procedure Official Journal L 226, 13/08/1987 P. 0002 - 0117.

14. Regulation 2286/03 Single Administrative Document - SAD.

15. Regulation New Computerised Transit System - NCTS 2008.

Статья поступила в редакциюю 2 декабря 2015 года. 